\title{
AN EVALUATION OF OVERLYING TISSUES TO DETERMINE FETAL EXPOSURE TO ULTRASOUND DURING THE THIRD TRIMESTER
}

\author{
IHAB R. KAMEL \\ Radiological Health, The School of Public Health, SPH-1, 109 S. Observatory St., Room 2533, \\ University of Michigan, Ann Arbor, MI, USA
}

(Received 19 August 1992; in final form 27 July 1993)

\begin{abstract}
Measurements of minimum and average total tissue thicknesses overlying the fetus during the third trimester were taken on 52 patients between 24 and 40 weeks gestation. Minimum total thickness of tissues constantly along the ultrasound path had a mean value of $1.75 \mathrm{~cm}$, ranging from 0.40 to $3.70 \mathrm{~cm}$. This corresponded to a mean attenuation of $0.87 \mathrm{~dB} \mathrm{MHz}^{-1}$, ranging from 0.30 to $1.68 \mathrm{~dB} \mathrm{MHz}^{-1}$. Average total thickness of tissues constantly along the ultrasound path had a mean value of $2.16 \mathrm{~cm}$, ranging from 1.00 to $4.10 \mathrm{~cm}$. This corresponded to a mean attenuation of $1.16 \mathrm{~dB} \mathrm{MHz}^{-1}$, ranging from 0.64 to $2.03 \mathrm{~dB}$ $\mathrm{MHz}^{-1}$. Average attenuation was also calculated for all soft tissues along the ultrasound path, including the placenta. The resulting average attenuation was $0.47 \mathrm{~dB} \mathrm{~cm}^{-1} \mathrm{MHz}^{-1}$. Maternal weight at the time of ultrasound examination had significant correlation with minimum and average ultrasound attenuation by tissues constantly along the ultrasound path. The $R^{2}$ value was $46.7 \%$ for minimum attenuation ( $p$-value $<\mathbf{0 . 0 0 0 1}$ ) and 53.3\% for average attenuation ( $p$-value $<0.0001$ ). Multiple regression analyses showed that the model that included maternal weight, prepregnancy weight and fetal gestational age was a better predictor of the amount of attenuation during the third trimester than the model that included maternal weight only. The $\mathbf{R}^{2}$ value of the model that included all three variables was $57.2 \%$ ( $p$-value $<0.0001$ ) for minimum attenuation, and $62.4 \%(p$-value $<0.0001)$ for average attenuation.
\end{abstract}

Key Words: Ultrasound, Ultrasonics, Ultrasonic diagnosis, Ultrasonic attenuation, Ultrasonic scanning, Ultrasonic tissue characterization, Pregnancy, Third trimester, Dosimetry.

\section{INTRODUCTION}

The use of ultrasound in clinical diagnosis, particularly for obstetric applications, has become very popular. Not only has the number of ultrasound examinations increased, but in recent years a tendency to improve imaging of diagnostic ultrasound instruments has led to an increase in the intensity of acoustic power output at which these devices operate. With the increasing number of patients exposed and with the trend to increase power output of diagnostic ultrasound devices, there has been an increase in the desire to maintain the relative safety of ultrasound, especially in sensitive situations such as pregnancy.

Ultrasound exposure may occur any time during pregnancy. Early in pregnancy damage to the fetus can be critical. Even though the fetal bones are not mineralized, the osteoid form of bone is rich in collagen, and the absorption coefficient of early fetal skeletal structures may be appreciable. However, this potential for tissue damage by ultrasound during organogenesis may be counteracted due to thick overlying tissues.
As gestation progresses, the fetal bones contain increasing mineral content and may become a significant source of tissue heating near the bone surface. Moreover, the amount of overlying tissue is expected to be thinner with the advance of pregnancy. Therefore, knowledge of exposure intensities and bone heating appear to be important throughout the period of gestation.

Under clinical conditions determination of temperature elevation is difficult because it requires knowledge of the in situ intensity. This is usually less than the corresponding water value due to attenuation caused by body tissues. Several estimates of ultrasound attenuation by tissues were reported in the literature. Some models were intended, specifically, for obstetrical applications. Earlier efforts were summarized by Stewart and Stratmeyer (1982) and the National Council on Radiation Protection (NCRP 1983). Those measurements were during the first trimester and yielded attenuation of $1 f$ to $7 f \mathrm{~dB}$ between the anterior abdominal wall and the location of the gestational sac, where $f$ is the ultrasound frequency in $\mathrm{MHz}$. 
More recently, attenuation estimates for the first and third trimester cases were made by Carson (1988), based on an informal search of reasonable worst cases in a few clinical examinations. These estimates yield a total minimum attenuation, at $3.5 \mathrm{MHz}$, of $3.9 \mathrm{~dB}$ in the first trimester and $1.6 \mathrm{~dB}$ in the third trimester. These correspond to a reduction in ultrasound power of $59 \%$ and $31 \%$ in the first and third trimesters, respectively.

The second trimester case was studied more extensively by Carson et al. (1989). Thicknesses of overlying tissues were measured in 22 pregnancies between 15 and 20 weeks of gestation. The study reported a minimum path length of attenuating tissue of $1.7 \mathrm{~cm}$, corresponding to a calculated attenuation at $3.5 \mathrm{MHz}$ of $2.8 \mathrm{~dB}$, or a $47 \%$ reduction in ultrasound power.

A similar thickness and attenuation study was performed by Smith et al. (1985) on scans from the literature. The mean attenuation at $3.5 \mathrm{MHz}$ varied approximately linearly from $12 \mathrm{~dB}$ at six weeks gestation to $10 \mathrm{~dB}$ at 35 weeks. High attenuation values were reported in this study because there was no attempt to obtain the image at a location of minimum attenuation path, and the placental attenuation probably was included.

The current study was designed to determine minimum ultrasound attenuation during the third trimester using a fixed-path model. The study also estimated average ultrasound attenuation using a homogeneoustissue model.

\section{PATIENTS AND METHODS}

The third trimester case was chosen in this study because of the limited information available on this trimester, and because the amount of overlying tissue is expected to be thinner than in the first and second trimesters. Calculation of ultrasound exposure to the fetus in the worst case where minimum tissue attenuation occurs is important for establishing safety criteria. It helps in estimating upper limits of the temperature elevation. The knowledge of average thickness is important in providing a realistic model on mean attenuation. The knowledge of thicknesses of various overlying tissue layers is also important for potential improvements in image quality. The thickness of fat layers determines the degree of effect on the focusing of all scanners and lateral distance measurements with sector scanners.

Sonograms of 52 pregnant patients undergoing ultrasound examination were chosen randomly from the literature. Scans were performed for different purposes and no standard protocol was followed for the examination. Choice was independent of maternal age, weight or height. Patients' ultrasound examinations during the third trimester, between 24 and 40 weeks, were selected. Patients' charts were reviewed to obtain personal information including maternal age, weight at the time of ultrasound examination (maternal weight), weight before pregnancy (prepregnancy weight) and maternal height. Only healthy females with single fetuses were included in this study.

The ultrasound units used were the Acuson 128 and the Aloka 650 . Transducer frequency was 3.5 or $5 \mathrm{MHz}$. Only third trimester scans performed with conventional linear and curvilinear scanners were included. Scans performed with sector scanners were not used in this study as different tissue layers are more difficult to differentiate reliably, and because direct contact sector scanning depresses the thickness of the overlying tissues by an average of $3.5 \mathrm{~mm}$ more than the linear scanner (Carson et al. 1989).

In each of the 52 cases, the first six to eight ultrasound views with identifiable overlying tissue layers were selected. The total thickness of tissues constantly overlying the fetus was measured for each view at the beam axis perpendicular to the surface of the skin. The average total overlying tissue of all eight views was then calculated. The views with the minimum and the average total tissue thickness were used to measure individual tissue layers, and two sets of data were generated. With respect to individual tissue thickness, the first and second sets had those of minimum and average total overlying tissues, respectively.

Tissues constantly overlying the fetus were grouped into skin, subcutaneous fat, abdominal muscle and uterine muscle. This is because these layers can be distinguished and because of the known differences in their attenuation coefficients. The skin thickness was not measured but was based on the values reported by Dines et al. (1984). In the ultrasound scanning conducted by Dines et al. (1984) on 11 normal adult skin sections, the minimum and average skin thicknesses were $0.121 \mathrm{~cm}$ and $0.230 \mathrm{~cm}$, respectively. Peritoneal fascia and abdominal muscle are difficult to differentiate from one another reliably, and therefore were combined. Attenuation due to reflections at tissue interfaces is negligible in the perpendicular path (NCRP 1983; Carson 1988; Smith et al. 1985) and was not included. Attenuation coefficient used to calculate attenuation in the skin is based on Pohlhammer and O'Brien (1980) and is $1.5 \mathrm{~dB} \mathrm{~cm}^{-1} \mathrm{MHz}^{-1}$. Attenuation coefficients for other tissue layers are the same as those used previously (NCRP 1983; Carson 1988). Those are 0.46, 0.51 and $0.29 \mathrm{~dB} \mathrm{~cm}^{-1} \mathrm{MHz}^{-1}$ for fat, muscle and myometrium, respectively.

The minimum total thickness results in minimal ultrasound attenuation. It was used to calculate weight- 
Table 1. Summary statistics for personal information of the 52 patients examined by ultrasound during the third trimester.

\begin{tabular}{lccccc}
\hline & \multicolumn{4}{c}{ Personal Information } \\
\cline { 2 - 6 } \multicolumn{1}{c}{ Statistics } & $\begin{array}{c}\text { Maternal age } \\
(\mathrm{y})\end{array}$ & $\begin{array}{c}\text { Maternal height } \\
(\mathrm{cm})\end{array}$ & $\begin{array}{c}\text { Maternal weight } \\
(\mathrm{kg})\end{array}$ & $\begin{array}{c}\text { Prepregnancy } \\
\text { weight }(\mathrm{kg})\end{array}$ & $\begin{array}{c}\text { Gestational age } \\
(\text { wk) }\end{array}$ \\
\hline Mean & 25.5 & 161.7 & 77.0 & 65.0 & 31.2 \\
Minimum & 16.0 & 152.4 & 56.7 & 44.4 & 23.6 \\
Maximum & 38.0 & 175.3 & 130.6 & 124.7 & 39.0 \\
Standard deviation & 6.0 & 6.7 & 18.9 & 18.8 & 4.3 \\
\hline
\end{tabular}

independent minimum ultrasound attenuation and, therefore, the maximum exposure the fetus is likely to receive. For conservatism, measurements of the placenta were not included in the calculation. Average total thickness was used to calculate the weight-independent average ultrasound attenuation and the average reduction in the beam intensity. In those measurements the thickness of all tissues from the skin to the first
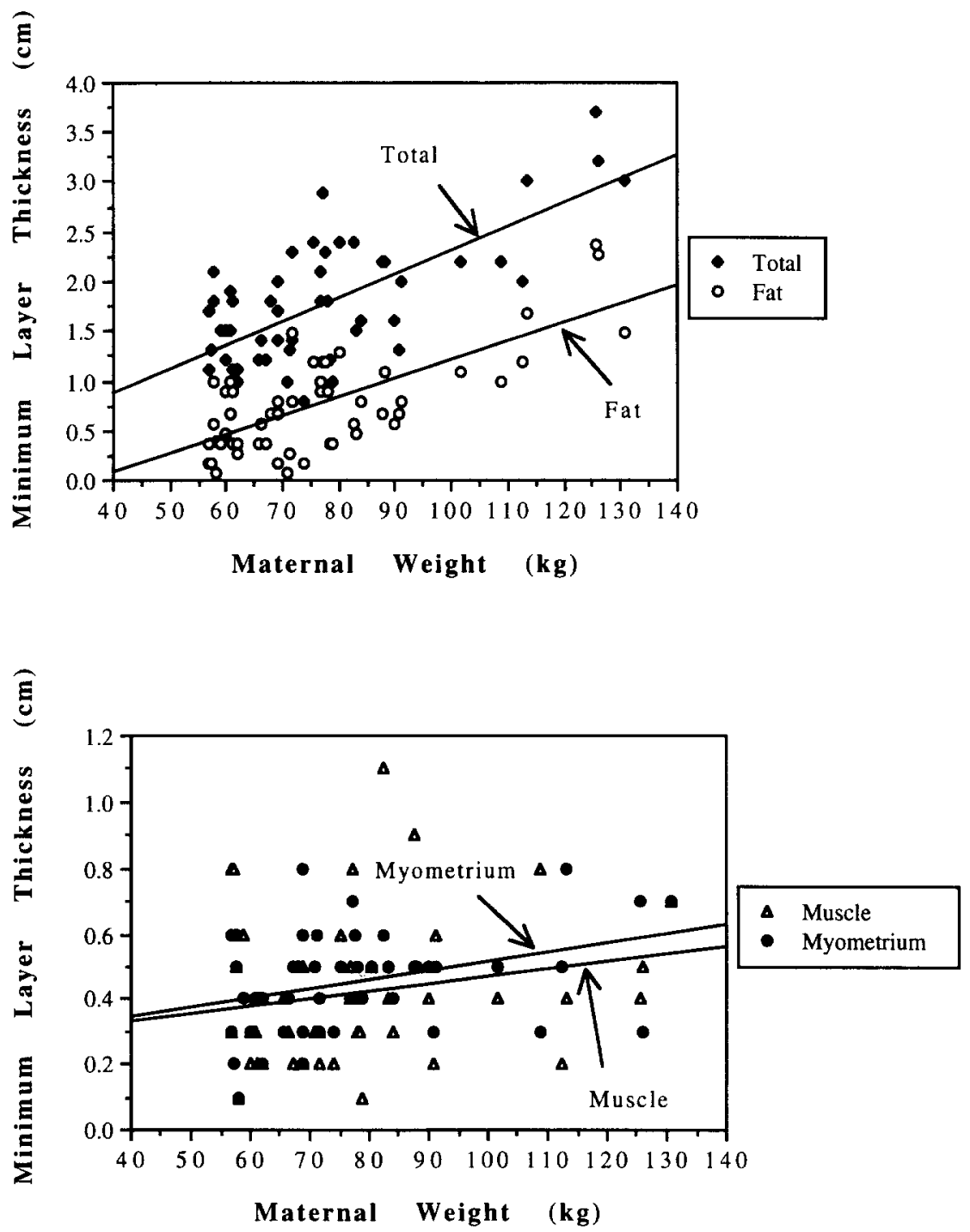

Fig. 1. Minimum total and individual overlying tissue thickness, excluding the skin, as a function of maternal weight. All measurements are along the beam axis from ultrasound views with the minimum total overlying tissue thickness. 
incidence of a fetal bone were measured along the beam axis. These measurements included the placenta and amniotic fluid.

Statistical analysis was performed on each set of data obtained to correlate total thicknesses of tissues constantly overlying the fetus, and the resulting attenuation with maternal weight, age, height, fetal gestational age and prepregnancy weight. Fetal gestational age was taken as the average of the four values reported by the ultrasound examination, which are the biparietal diameter, the head circumference, the abdominal circumference and the femoral length. Multiple regression analysis was performed to determine the independent variables that were related to the minimum and average total overlying tissue attenuation. These variables would contribute information for the prediction of weight-dependent total ultrasound attenuation by tissues constantly along the ultrasound path.

\section{RESULTS}

In the measurements to determine the thickness of tissue overlying the fetus during the third trimester, the total and individual abdominal tissue thicknesses were measured in 52 patients. Summary statistics for personal data including maternal age, height, weight, prepregnancy weight and gestational age are shown in Table 1.

Figure 1 shows minimum individual measurements of overlying tissue layers and total minimum overlying tissue thickness during the third trimester as a function of maternal weight. Linear regressions
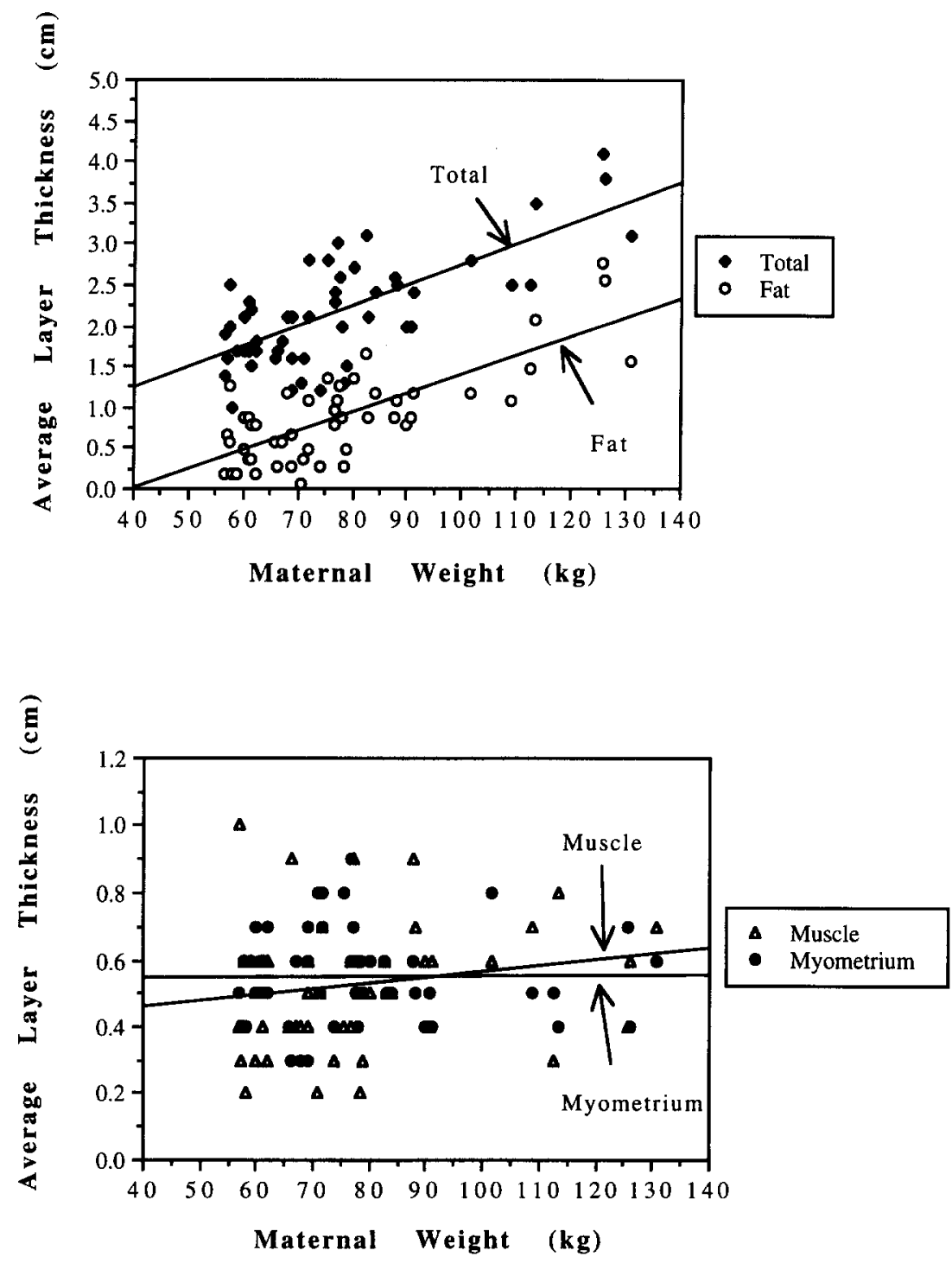

Fig. 2. Average total and individual overlying tissue thickness, excluding the skin, as a function of maternal weight for the same group of patients. 
Table 2. Linear regression analyses of the minimum and average thickness of tissue layers constantly overlying the fetus as a function of maternal weight during the third trimester. Tissue thicknesses can be estimated using eqn (1).

\begin{tabular}{lccccc}
\hline \multicolumn{1}{c}{$\begin{array}{c}\text { Maternal weight } \\
\text { coefficient } \\
\left(\mathrm{cm} \mathrm{kg}^{-1}\right)\end{array}$} & $\begin{array}{c}\text { Constant } \\
(\mathrm{cm})\end{array}$ & $\begin{array}{c}\mathbf{R}^{2} \\
(\%)\end{array}$ & $F$ ratio & $p$-value \\
\hline Missue layer & & & & & \\
$\quad$ Total & 0.024206 & -0.11128 & 47.1 & 44.5 & $<0.0001$ \\
Subcutaneous fat & 0.018586 & -0.66465 & 50.8 & 51.5 & $<0.0001$ \\
Abdominal muscle & 0.002299 & 0.23629 & 4.1 & 2.1 & $<0.20$ \\
$\quad$ Myometrium & 0.002878 & 0.22436 & 13.0 & 7.5 & $<0.01$ \\
Average thickness & & & & & \\
Total & 0.024952 & 0.23694 & 51.4 & 52.8 & $<0.0001$ \\
Subcutaneous fat & 0.023305 & -0.93919 & 58.5 & 70.4 & $<0.0001$ \\
Abdominal muscle & 0.001767 & 0.38497 & 3.2 & 1.7 & $<0.25$ \\
Myometrium & 0.000090 & 0.53922 & 0.0 & 0.0 & $<0.95$ \\
\hline
\end{tabular}

covering all subjects up to a maternal weight of 130.6 $\mathrm{kg}$ are shown. Average total and individual tissue thickness as a function of maternal weight are shown in Fig. 2. Coefficients of the linear regressions for minimum and average thicknesses of tissues constantly along the ultrasound path are given in Table 2. The linear regression equation is

$$
\mathrm{TT}=(\mathrm{WC} \times \mathrm{MW})+\mathrm{C},
$$

where:

$$
\begin{aligned}
\text { TT } & =\text { tissue thickness }(\mathrm{cm}) ; \\
\text { WC } & =\text { weight coefficient }\left(\mathrm{cm} \mathrm{kg} \mathrm{kg}^{-1}\right) ; \\
\text { MW } & =\text { maternal weight }(\mathrm{kg}) ; \text { and } \\
\mathrm{C} & =\text { constant }(\mathrm{cm}) .
\end{aligned}
$$

Minimum total and subcutaneous tissue thickness also correlated significantly with prepregnancy weight; the $\mathrm{R}^{2}$ values were $39.3 \%$ and $45.0 \%$, respectively. The $p$-value was $<0.0001$ for both correlations. Higher $R^{2}$ values were obtained when average total and subcutaneous tissue thicknesses were correlated with prepregnancy weight; the $\mathrm{R}^{2}$ values were $43.5 \%$ and $48.8 \%$, respectively. The $p$-value for both correlations was also $<0.0001$.
Total attenuation of the ultrasound beam intensity was calculated using the measured thicknesses of tissues constantly overlying the fetus. Table 3 shows the data for minimum layer thickness and the calculated minimum attenuation values for all tissues constantly along the ultrasound path except the skin. Also shown is the percent reduction in ultrasound intensity at 3.5 MHz. Table 4 shows the data for the average layer thickness and the corresponding attenuation values. Total overlying tissue and the corresponding attenuation was calculated for tissues constantly along the ultrasound path. Attenuation was also calculated for all tissues along the ultrasound path including the placenta, which was present in 17 of the 52 views, and the amniotic fluid, which was in 14 of the 52 views studied. Figure 3 shows ultrasound attenuation as a function of fetal depth.

Figures 4 and 5 show the calculated minimum and average total attenuation for ultrasound beam as a function of maternal weight at the time of examination. Also shown are the $95 \%$ confidence and prediction intervals for the regression lines (Neter et al. 1990). The $\mathrm{R}^{2}$ values were $46.7 \%$ and $53.3 \%$ for minimum and average total attenuation, respectively. The $p$-value

\begin{tabular}{|c|c|c|c|c|c|c|c|}
\hline \multirow[b]{2}{*}{ Tissue } & \multicolumn{3}{|c|}{$\begin{array}{l}\text { Minimum thickness } \\
(\mathrm{cm})\end{array}$} & \multicolumn{2}{|c|}{$\begin{array}{l}\text { Attenuation } \\
\left(\mathrm{dB} \mathrm{MHz}{ }^{-1}\right)\end{array}$} & \multicolumn{2}{|c|}{$\begin{array}{c}\text { Intensity reduction } \\
\text { at } 3.5 \mathrm{MHz}\end{array}$} \\
\hline & Mean & Range & SD & Mean & Range & Mean $(\%)$ & Range (\%) \\
\hline Total & 1.75 & $0.40-3.70$ & 0.67 & 0.87 & $0.30-1.68$ & 50.4 & $21.5-74.2$ \\
\hline Subcutaneous fat & 0.77 & $0.08-2.38$ & 0.49 & 0.35 & $0.04-1.09$ & & \\
\hline Abdominal muscle & 0.41 & $0.10-1.10$ & 0.22 & 0.21 & $0.05-0.56$ & & \\
\hline Myometrium & 0.45 & $0.10-0.80$ & 0.15 & 0.13 & $0.03-0.23$ & & \\
\hline
\end{tabular}
was $<0.0001$ for both regressions. Coefficients of the

Table 3. Minimum measured tissue thickness and calculated attenuation of intervening tissue, except for the skin. Skin thickness was taken as $0.121 \mathrm{~cm}$, and the attenuation was $0.1815 \mathrm{~dB} \mathrm{MHz}^{-1}$. Also shown is reduction in intensity at $3.5 \mathrm{MHz}$. 
Table 4. Average measured tissue thickness and calculated attenuation of intervening tissue, except for the skin. Skin thickness was taken as $0.23 \mathrm{~cm}$, and the attenuation was $0.345 \mathrm{~dB} \mathrm{MHz}^{-1}$. Also shown is reduction in intensity at $3.5 \mathrm{MHz}$. Mean tissue attenuation coefficient was calculated for tissues constantly along the ultrasound path (a), for all nonfluid path (b) and for ultrasound path including fluid (c) to be $0.54,0.47$ and $0.40 \mathrm{~dB} \mathrm{~cm}^{-1} \mathrm{MHz}^{-1}$, respectively.

\begin{tabular}{|c|c|c|c|c|c|c|c|}
\hline \multirow[b]{2}{*}{ Tissue } & \multicolumn{3}{|c|}{$\begin{array}{l}\text { Average thickness } \\
(\mathrm{cm})\end{array}$} & \multicolumn{2}{|c|}{$\begin{array}{l}\text { Attenuation } \\
\left(\mathrm{dB} \mathrm{MHz} z^{-1}\right)\end{array}$} & \multicolumn{2}{|c|}{$\begin{array}{l}\text { Intensity reduction } \\
\text { at } 3.5 \mathrm{MHz}(\%)\end{array}$} \\
\hline & Mean & Range & $\mathrm{SD}$ & Mean & Range & Mean & Range \\
\hline Total (wall \& myometrium) (a) & 2.16 & $1.00-4.10$ & 0.66 & 1.16 & $0.64-2.03$ & 60.7 & $40.3-80.5$ \\
\hline Total (nonfluid path) (b) & 2.95 & $1.00-8.20$ & 1.71 & 1.39 & $0.64-3.18$ & 67.4 & $40.3-92.3$ \\
\hline Total (including fluid path) (c) & 3.49 & $1.00-10.2$ & 2.28 & 1.39 & $0.64-3.19$ & 67.4 & $40.3-92.3$ \\
\hline Subcutaneous fat & 0.86 & $0.07-2.77$ & 0.58 & 0.39 & $0.03-1.27$ & & \\
\hline Abdominal muscle & 0.52 & $0.20-1.00$ & 0.19 & 0.27 & $0.10-0.51$ & & \\
\hline Myometrium & 0.55 & $0.30-0.90$ & 0.14 & 0.16 & $0.09-0.26$ & & \\
\hline Placenta $(n=17)$ & 2.42 & $0.90-4.70$ & 1.41 & 0.70 & $0.26-1.36$ & & \\
\hline Amniotic fluid $(n=14)$ & 2.00 & $0.50-4.30$ & 1.34 & 0.004 & $0.001-0.009$ & & \\
\hline
\end{tabular}
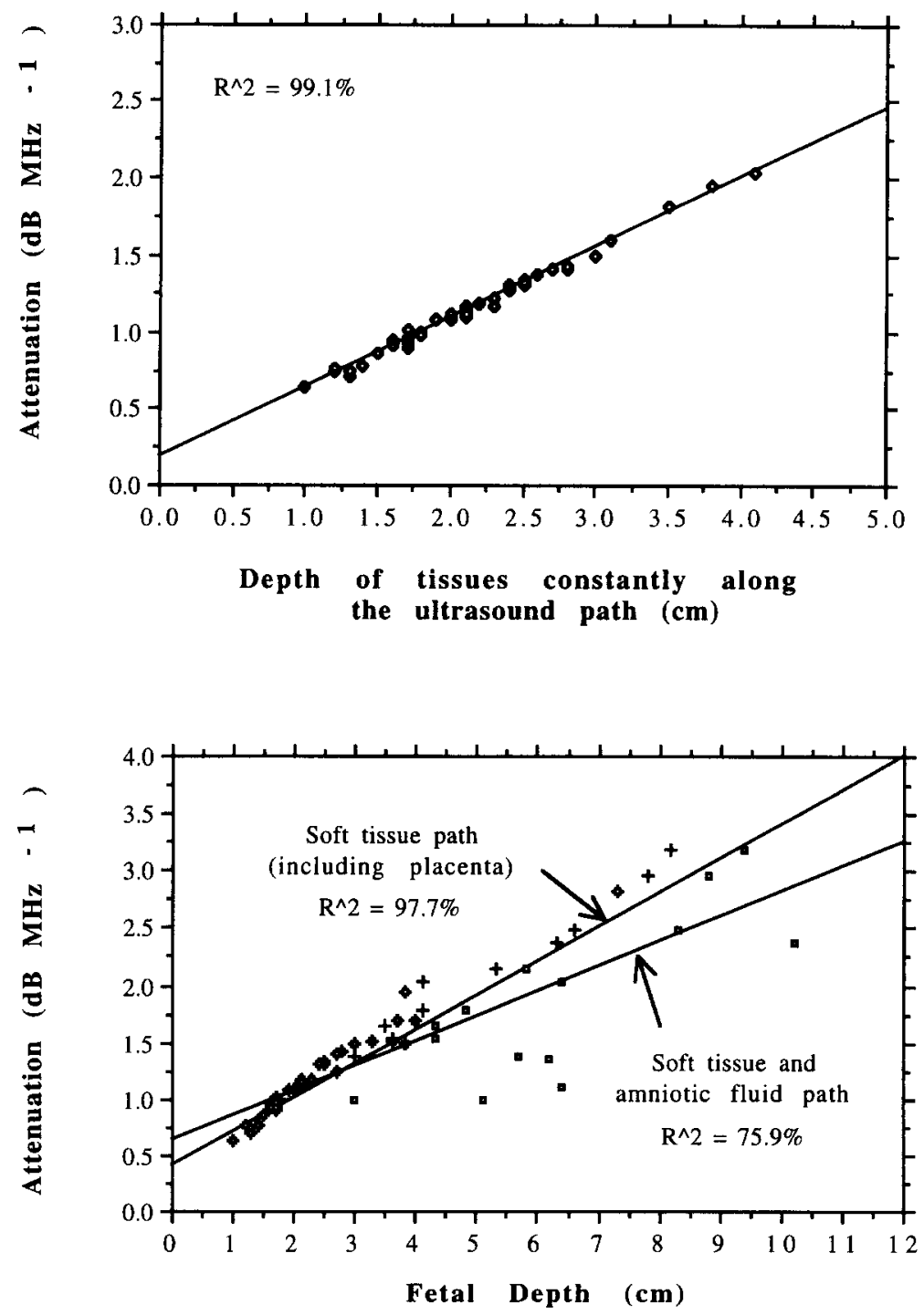

Fig. 3. Ultrasound attenuation as a function of fetal depth with and without the placenta and amniotic fluid path. 


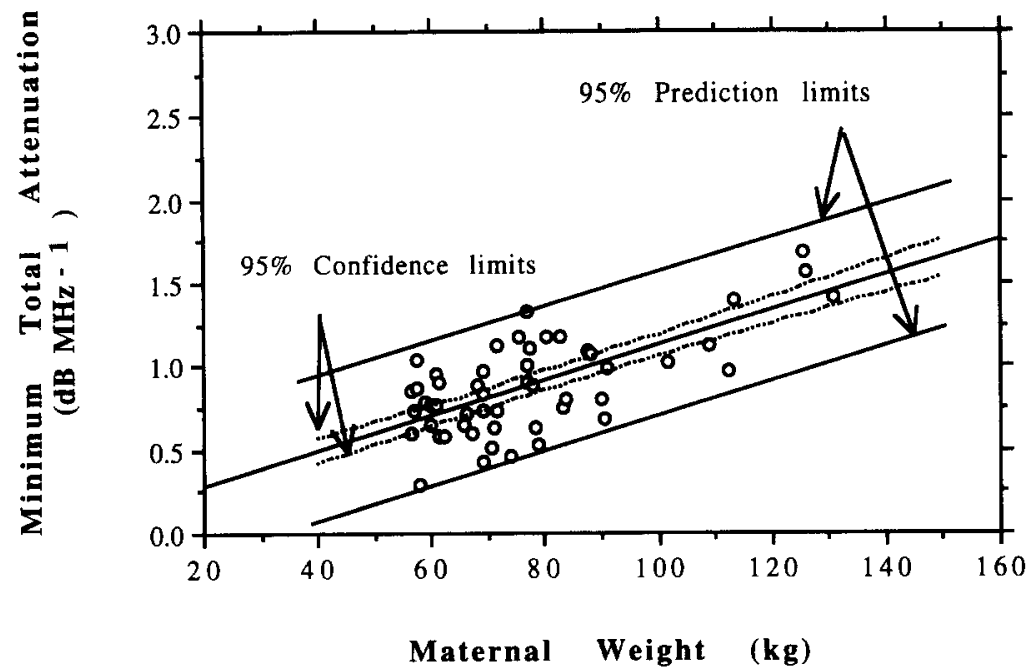

Fig. 4. Minimum attenuation of ultrasound intensity by overlying tissue as a function of maternal weight. The 95\% confidence and prediction intervals are also shown.

linear regressions for minimum and average attenuation as a function of maternal weight are given in Table 5 . The linear regression equation is

$$
\mathrm{TA}=(\mathrm{WC} \times \mathrm{MW})+\mathrm{C},
$$

where:

$\mathrm{TA}=$ tissue attenuation $\left(\mathrm{dB} \mathrm{MHz}{ }^{-1}\right)$

$\mathrm{WC}=$ weight coefficient $\left(\mathrm{dB} \mathrm{MHz}{ }^{-1} \mathrm{~kg}^{-1}\right)$;

MW = maternal weight $\left(\mathrm{kg}^{-1}\right)$; and

$\mathrm{C}=$ constant $\left(\mathrm{dB} \mathrm{MHz}{ }^{-1}\right)$.

Fetal gestational age had low correlation with minimum and average total attenuation, the $R^{2}$ values were $0.9 \%$ ( $p$-value $<0.5$ ) and 2.0\% ( $p$-value $<0.35$ ), respectively. Minimum total attenuation had weak correlation with maternal age $\left(\mathrm{R}^{2}=4.5 \%\right)$ and maternal height $\left(\mathrm{R}^{2}=0.3 \%\right)$. Average total attenuation also had weak correlation with maternal age $\left(\mathrm{R}^{2}=5.8 \%\right)$ and maternal height $\left(R^{2}=0.3 \%\right)$.

Five independent variables were included in the multiple regression analyses to determine the best model that could predict ultrasound attenuation by tissues constantly along the ultrasound path. Those variables were maternal age, weight, height, prepregnancy weight and gestational age. In this sample of the population, the model for predicting total ultrasound attenu-

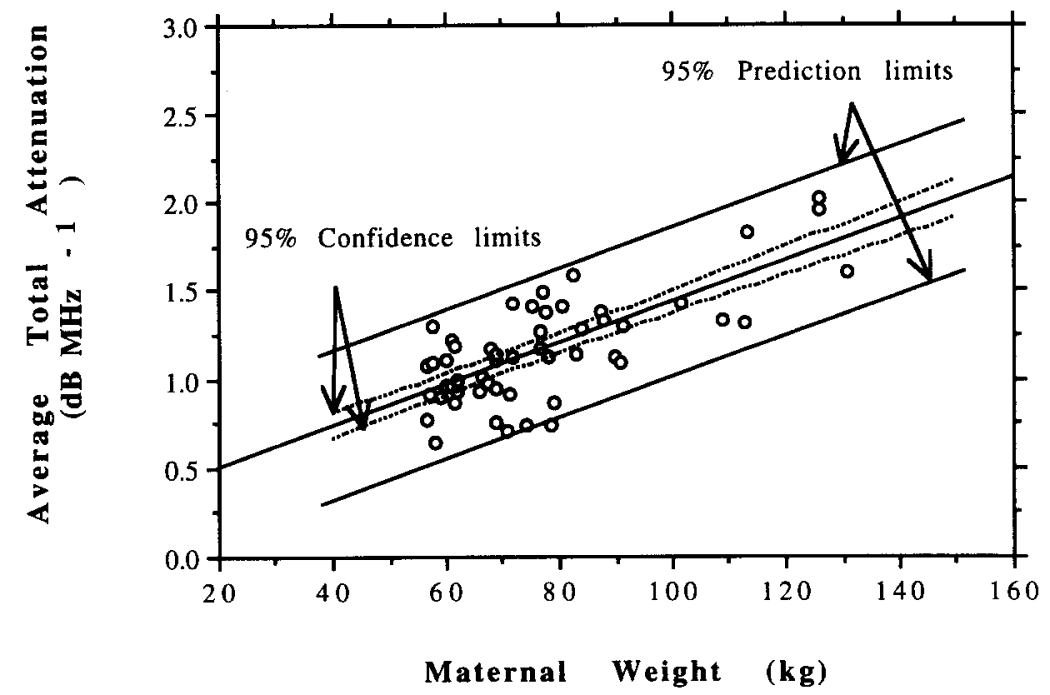

Fig. 5. Average attenuation of ultrasound intensity by overlying tissue as a function of maternal weight. The $95 \%$ confidence and prediction intervals are also shown. 
Table 5. Simple linear regression analyses for minimum and average total attenuation by tissues constantly along the ultrasound path as a function of maternal weight for patients during the third trimester. Total attenuation can be estimated using eqn (2).

\begin{tabular}{lccccr}
\hline $\begin{array}{c}\text { Total attenuation } \\
(\mathrm{dB} \mathrm{MHz})^{-1}\end{array}$ & $\begin{array}{c}\text { Maternal weight } \\
\text { coefficient } \\
\left(\mathrm{dB} \mathrm{MHz}^{-1} \mathrm{~kg}^{-1}\right)\end{array}$ & $\begin{array}{c}\text { Constant } \\
\left(\mathrm{dB} \mathrm{MHz}^{-1}\right)\end{array}$ & $\begin{array}{c}\mathrm{R}^{2} \\
(\%)\end{array}$ & $F$ ratio & $p$-value \\
\hline Minimum tissue thickness & 0.010557 & 0.061493 & 46.7 & 43.8 & $<0.0001$ \\
Average tissue thickness & 0.011648 & 0.265479 & 53.3 & 57.2 & $<0.0001$ \\
\hline
\end{tabular}

ation included maternal weight, gestational age and prepregnancy weight. The $\mathrm{R}^{2}$ value was $57.2 \%(p$ value $<0.0001$ ) for minimum attenuation, and $62.4 \%$ ( $p$-value $<0.0001$ ) for average attenuation. Tables 6 and 7 show the output of the multiple regression analyses for the minimum and average total attenuation, respectively. The multiple regression model is given by eqn (3):

$$
\begin{aligned}
\mathrm{TA}=(\mathrm{WC} \times \mathrm{MW})+(\mathrm{AC} \times \mathrm{AG}) & \\
& +(\mathrm{PC} \times \mathrm{PW})+\mathrm{C},
\end{aligned}
$$

where:

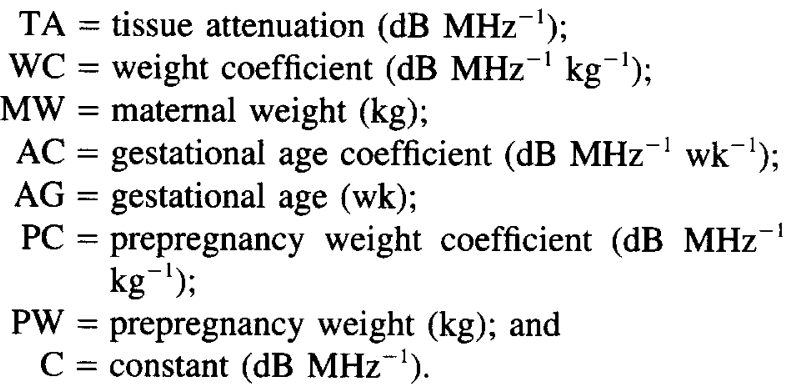

\section{DISCUSSION}

Hyperthermia is a major biological effect of ultrasound. The potential risk to the human conceptus is of special concern because it often receives whole body

Table 6. Multiple regression analysis for minimum total tissue attenuation as a function of maternal weight, prepregnancy weight and fetal gestational age. Total

\begin{tabular}{|c|c|c|c|}
\hline \multicolumn{4}{|c|}{ Dependent variable: Minimum total attenuation } \\
\hline \multirow[b]{2}{*}{ Variable } & \multicolumn{2}{|c|}{$\begin{array}{l}\text { Overall } \mathrm{R}^{2}=57.2 \% \\
F \text { ratio }=21.4 \\
p \text {-value }<0.0001\end{array}$} & \multirow[b]{2}{*}{$T$-Ratio } \\
\hline & Coefficient & Model $\mathbf{R}^{2}$ & \\
\hline Constant & 0.565499 & & 2.778 \\
\hline Maternal weight & 0.021593 & $46.7 \%$ & 4.040 \\
\hline Gestational age & -0.025525 & $54.7 \%$ & -3.324 \\
\hline Prepregnancy wt. & -0.008568 & $57.2 \%$ & -1.676 \\
\hline
\end{tabular}
attenuation can be estimated using eqn (3). exposure to ultrasound, and because the mammalian conceptus has little control of its own body temperature. Bone has a unique role in ultrasonic heating. It has an unusually large absorption coefficient and is probably the site of highest potential temperature elevation during an application of ultrasound (NCRP 1992). Drewniak et al. (1989) exposed a human fetal femur in vitro to $1 \mathrm{MHz}$ ultrasound and measured the temperature rise by thermocouples. The study reported that the temperature rise in human fetal femur was nearly linear with the ultrasonic intensity of exposure; the rate of rise was approximately quadratic with gestational age. It is clear that exposure of bone represents a critical situation for safety from a thermal standpoint. With the progress of pregnancy and the advance in fetal bone development, the potential for thermal damage is expected to increase significantly. Soft tissues at bone interfaces are also at risk of hyperthermia. This is especially important for soft tissues surrounded by bone as in the case of the pituitary gland, which is enclosed in the sella turcica.

Temperature rise produced by ultrasound can be determined by measuring in situ values of acoustic intensity or power. However, due to the inherent difficulties of these measurements in obstetric applications, the alternative is to estimate the attenuation in tissues along the ultrasound path. Estimating ultrasound attenuation and the corresponding fetal exposure are of

Table 7. Multiple regression analysis for average total tissue attenuation as a function of maternal weight, prepregnancy weight and fetal gestational age.

\begin{tabular}{|c|c|c|c|}
\hline \multicolumn{4}{|c|}{ Dependent variable: Average total attenuation } \\
\hline \multirow[b]{2}{*}{ Variable } & \multicolumn{3}{|c|}{$\begin{array}{l}\text { Overall } \mathrm{R}^{2}=62.4 \% \\
F \text { ratio }=26.6 \\
p \text {-value }<0.0001\end{array}$} \\
\hline & Coefficient & Model $\mathrm{R}^{2}$ & $T$-Ratio \\
\hline Constant & 0.739767 & & 3.754 \\
\hline Maternal weight & 0.022628 & $53.3 \%$ & 4.373 \\
\hline Gestational age & -0.024239 & $60.0 \%$ & -3.260 \\
\hline Prepregnancy wt. & -0.008662 & $62.4 \%$ & -1.751 \\
\hline
\end{tabular}
Total attenuation can be estimated using eqn (3). 
value in providing estimates of safety margins and risks of ultrasound exposure.

In the examination of the fetus, it is appropriate to assume the existence of nonattenuating fluid for much of the path followed by the ultrasound beam before it reaches the fetus. A fixed-path model is usually used in which the minimum attenuation along the path from the transducer to the fetus is independent of the distance (NCRP 1992; Barnett and Kossoff 1992). This model assumes that the minimum path length of attenuating tissues does not change greatly during pregnancy, while the path length of essentially nonattenuating tissue depends greatly on conditions such as the extent of bladder filling or the position of the relevant fetal anatomy within the uterus and amniotic fluid (NCRP 1992; Carson 1988). Attenuation is expressed in $\mathrm{dB} \mathrm{MHz}{ }^{-1}$. In situations where the ultrasound path is primarily through soft tissue and traverses little or no fluid, a homogeneous-tissue model is appropriate (NCRP 1992). Attenuation in this case is expressed in $\mathrm{dB} \mathrm{cm}{ }^{-1} \mathrm{MHz}^{-1}$.

In this work, minimum ultrasound attenuation was calculated for tissues constantly along the ultrasound path, assuming a fixed-path model. The placenta was not considered in the calculations because in worst case conditions it will not be along the beam axis. Average tissue attenuation was calculated for tissues constantly along the ultrasound path assuming a fixedpath model, and for all tissues overlying the fetus, including the placenta, assuming a homogeneous-tissue model.

In the assessment of minimum overlying tissue thickness, subcutaneous fat had better correlation than muscle and myometrium when correlated with maternal weight. Minimum subcutaneous fat had a significant correlation with maternal weight at the time of examination $\left(\mathrm{R}^{2}=50.8 \%, p\right.$-value $\left.<0.0001\right)$ and resulted in good correlation of minimum total thickness with maternal weight $\left(\mathrm{R}^{2}=47.1 \%, p\right.$-value $\left.<0.0001\right)$. Eight of the 52 patients examined had maternal weight above $90 \mathrm{~kg}$ and prepregnancy weight above $80 \mathrm{~kg}$. When these cases were excluded, the $\mathrm{R}^{2}$ value of subcutaneous fat as a function of maternal weight dropped to $10.9 \%$. This suggested that for females below 90 $\mathrm{kg}$ there is less significant correlation between body weight and the amount of subcutaneous fat. Obese females contributed significantly to the correlation between fat and maternal weight during the third trimester. They were not excluded from the study because they represented the upper extreme of maternal weight in this random sample of the population. Excluding these cases would restrict the variance, which would subsequently restrict the correlation. Diagnostic studies were carried out to detect any influential outlying observations. None were detected.

The relation between average individual layer thickness and maternal weight also showed more significant correlation for fat than muscle and myometrium. Average subcutaneous fat had a higher $R^{2}$ value $(58.5 \%)$ than minimum subcutaneous fat $(50.8 \%)$ when correlated with maternal weight, because the further the measurements are from the mean, the greater the uncertainty associated with them. Average measures are more stable than extreme measures and are better indicators of the actual population mean. Because of the significant correlation of the average subcutaneous fat and maternal weight $\left(\mathrm{R}^{2}=58.5 \%, p\right.$ value $<0.0001$ ), the latter can be used to estimate the former. Using eqn (1) and the data in Table 2, it can be calculated that an 80-kg-pregnant female in the third trimester would have an average subcutaneous fat thickness of $0.93 \mathrm{~cm}$. These estimates are valid between the maternal weight of 50 and $130 \mathrm{~kg}$. However, extrapolation beyond this range is not valid.

Minimum total and subcutaneous fat thickness had less significant correlation with prepregnancy weight compared to the correlation of these layers with maternal weight. This is because maternal weight at the time of examination accounts for the weight gained by the patient during the third trimester and, therefore, results in better correlation with subcutaneous fat. As might be expected, average total and fat thickness had better correlation with prepregnancy weight compared to minimum total and fat thickness.

Attenuation values of the ultrasound beam in $\mathrm{dB}$ $\mathrm{MHz}^{-1}$ were calculated for the minimum total tissues constantly overlying the fetus. The calculated weightindependent minimum attenuation for the 52 cases had a minimum value of $0.30 \mathrm{~dB} \mathrm{MHz}$. This indicates that one can count on at least $21.5 \%$ reduction of ultrasound power and intensity at and above the usual 3.5 $\mathrm{MHz}$ imaging frequency. This value is less than that suggested by Carson (1988), which is $0.47 \mathrm{~dB} \mathrm{MHz}^{-1}$ from an overlying tissue of $1.0 \mathrm{~cm}$ thickness, i.e., about $31.5 \%$ reduction in beam intensity at $3.5 \mathrm{MHz}$. The $21.5 \%$ reduction in ultrasound power and intensity reported in this study is also less than that reported by Carson et al. (1989) of $47.5 \%$ during the second trimester. This is due to the stretch of overlying tissue during the third trimester, which results in less tissue attenuation.

Average attenuation reported in this study had a mean value of $1.16 \mathrm{~dB} \mathrm{MHz}^{-1}$ for the measured thickness of $2.16 \mathrm{~cm}$ of tissues constantly along the ultrasound path. Assuming a homogeneous tissue model, this resulted in an average attenuation coefficient of $0.54 \mathrm{~dB} \mathrm{~cm}^{-1} \mathrm{MHz}^{-1}$. When the ultrasound path along 
the placenta was accounted for, and using an attenuation coefficient for the placenta of $0.28 \mathrm{~dB} \mathrm{~cm}^{-1}$ $\mathrm{MHz}^{-1}$ (Duck 1990), the resulting total tissue attenuation coefficient was $0.47 \mathrm{~dB} \mathrm{~cm}^{-1} \mathrm{MHz}^{-1}$. However, it is more appropriate to use a fixed-path model than a homogeneous-tissue model for obstetric applications.

In situ measurements during routine nonpregnant ultrasound examination were performed by Siddiqi et al. (1992) and resulted in calculated mean attenuation coefficient of 1.39 and $0.14 \mathrm{~dB} \mathrm{~cm}^{-1} \mathrm{MHz}^{-1}$ for the abdominal wall and myometrium, respectively. Using regression analyses of the data, the predicted attenuation coefficient of the abdominal wall and myometrium were 1.17 and $0.52 \mathrm{~dB} \mathrm{~cm}^{-1} \mathrm{MHz}^{-1}$, respectively. The predicted overall attenuation coefficient of all tissues combined was $0.77 \mathrm{~dB} \mathrm{~cm}^{-1} \mathrm{MHz}^{-1}$, and is more than that reported in this study of $0.54 \mathrm{~dB} \mathrm{~cm}^{-1} \mathrm{MHz}^{-1}$ for tissues constantly along the ultrasound path. However, our result is higher than that reported by Siddiqi et al. (1991) in ovarian ultrasound examination under empty bladder condition $\left(0.45 \mathrm{~dB} \mathrm{~cm}^{-1} \mathrm{MHz}^{-1}\right)$.

The Food and Drug Administration (FDA 1985) and the American Institute of Ultrasound in Medicine (AIUM 1992) use a homogeneous-tissue model for regulatory purposes. In the calculation of all mechani$\mathrm{cal}$ and thermal indices, the average ultrasonic attenuation is assumed in the above model to be $0.3 \mathrm{~dB} \mathrm{~cm}^{-1}$ $\mathrm{MHz}^{-1}$ along the beam axis in the body. This coefficient lies between the values for soft tissues and the very small values that apply to urine and amniotic fluid. This model is not conservative in comparison with the present estimates. In a typical case of 3.5 $\mathrm{MHz}$ frequency and $7 \mathrm{~cm}$ focal length, the above model indicates ultrasound attenuation of $7.4 \mathrm{~dB}$, or an intensity reduction of $81.8 \%$, compared with the worst case measured in this study of only $21.5 \%$. However, an average attenuation of $0.3 \mathrm{~dB} \mathrm{~cm} \mathrm{dmz}^{-1}$ is considered conservative compared to the results of this study of $0.47 \mathrm{~dB} \mathrm{~cm}^{-1} \mathrm{MHz}^{-1}$.

Calculated minimum total attenuation correlated well with maternal weight $\left(\mathrm{R}^{2}=46.7 \%, p\right.$-value $<0.0001$ ). This weight-dependent ultrasound attenuation is valuable in estimating in situ exposure levels given a particular patient. Using eqn (2) and Table 5, the minimum total attenuation of an $80-\mathrm{kg}$-pregnant female is calculated to be $0.91 \mathrm{~dB} \mathrm{MHz}^{-1}$. The $95 \%$ confidence interval is estimated, using Fig. 4 , to be between 0.85 and $0.95 \mathrm{~dB} \mathrm{MHz}^{-1}$. It can be predicted that $95 \%$ of the time an $80-\mathrm{kg}$-pregnant female selected randomly from the population would have a minimum attenuation ranging from 0.50 to $1.31 \mathrm{~dB} \mathrm{MHz}^{-1}$.

Average total attenuation had a better correlation with maternal weight $\left(\mathrm{R}^{2}=53.3 \%, p\right.$-value $\left.<0.0001\right)$ compared to minimum total attenuation $\left(R^{2}=46.7 \%\right.$, $p$-value $<0.0001)$. By performing similar calculations, it can be expected that an 80-kg-pregnant female would have an average total attenuation of $1.20 \mathrm{~dB} \mathrm{MHz}^{-1}$ ranging from 1.12 to $1.25 \mathrm{~dB} \mathrm{MHz}^{-1}$. With the confidence coefficient of $95 \%$, an $80-\mathrm{kg}$-pregnant female selected randomly from the population would be expected to have an average total attenuation between 0.78 and $1.61 \mathrm{~dB} \mathrm{MHz}^{-1}$.

Gestational age reported in this study is based on four fetal measurements by ultrasound and is usually reported with a range of \pm 3 weeks. This is a possible cause of the weak correlation between subcutaneous fat thickness and gestational age. Another possible reason for this weak correlation is that the subcutaneous fat is deposited in the abdominal wall only up to 30 weeks, after which there is little or no increase. Over the abdomen, the skin fold thickness increases by about $40 \%$ during these 30 weeks. As the product of conception makes its final spurt of growth in the last 10 weeks, maternal storage slows down (Dewhurst 1980).

The low correlation value between subcutaneous fat and gestational age subsequently resulted in an insignificant correlation between total attenuation and gestational age. The correlation between total attenuation and prepregnancy weight was also insignificant. However, multiple regression analysis showed that the best model to predict minimum total attenuation includes maternal weight, gestational age and prepregnancy weight. The same three variables are the best predictors of average total attenuation. From the above multiple regression models and using eqn (3) and Tables 6 and 7, minimum and average total attenuation by tissues constantly along the ultrasound path can be calculated for a particular patient. An $80-\mathrm{kg}$ pregnant female in her 30th week of gestation and whose prepregnancy weight is $65 \mathrm{~kg}$ would be expected to have a minimum attenuation of $0.97 \mathrm{~dB}$ $\mathrm{MHz}^{-1}$, and an average attenuation of $1.26 \mathrm{~dB} \mathrm{MHz}^{-1}$.

\section{SUMMARY}

The distributions of the minimum and average overlying tissue thicknesses were measured in 52 patients during the third trimester. Minimum ultrasound attenuation was calculated for tissues constantly along the ultrasound path, assuming a fixed-path model. Attenuation had a mean value of $0.87 \mathrm{~dB} \mathrm{MHz}^{-1}$, ranging from 0.30 to $1.68 \mathrm{~dB} \mathrm{MHz}^{-1}$. The minimum attenuation of $0.30 \mathrm{~dB} \mathrm{MHz}^{-1}$ accounts for $21.5 \%$ reduction in ultrasound intensity at $3.5 \mathrm{MHz}$. Average ultrasound attenuation was calculated for all tissues along the ultrasound path, including the placenta, and assuming a homogeneous-tissue model. Average attenuation coefficient for the nonfluid path was $0.47 \mathrm{~dB} \mathrm{~cm}^{-1} \mathrm{MHz}^{-1}$. 
Maternal weight at the time of ultrasound examination had significant correlation with minimum and average ultrasound attenuation by tissues constantly along the ultrasound path, and can be used to predict the percent reduction in ultrasound intensity reaching the fetus. However, multiple regression analyses showed that the model that included maternal weight, prepregnancy weight and fetal gestational age was a better predictor of the amount of attenuation during the third trimester than the model that included maternal weight only.

Acknowledgements - I owe special thanks to P. L. Carson, Ph.D., for his assistance and valuable suggestions throughout the course of this work. My deepest appreciation is expressed to A. P. Jacobson, Ph.D., and J. E. Martin, Ph.D., for their guidance and support. My gratitude is extended to J. Miklos, MPH, for his critical comments, which helped clarify the manuscript.

\section{REFERENCES}

American Institute of Ultrasound in Medicine (AIUM) Standard for real-time display of thermal and mechanical acoustic output indices on diagnostic ultrasound equipment. Rockville, MD: AIUM; 1992.

Barnett, S. B.; Kossoff, G., eds. WFUMB Symposium on safety and standardization in medical ultrasound. Issues and recommendations regarding thermal mechanisms for biological effects of ultrasound (30 August-1 September 1991). Ultrasound Med. Biol. $18: 731-810 ; 1992$.

Carson, P. L. Medical ultrasound fields and exposure measurements. In: Proceedings Twenty-Second Annual Meeting of NCRP (April 1-2, 1986); NCRP, Bethesda, MD; 1988:287-307.

Carson, P. L.; Rubin, J. M.; Chiang, E. H. Fetal depth and ultrasound path lengths through overlying tissues. Ultrasound Med. Biol. 15:629-639; 1989.

Dewhurst, J. Weight gain in pregnancy. In: Hytten, F.; Chamberlain,
G., eds. Clinical physiology in obstetrics. St. Louis: Blackwell Scientific Publications; 1980:193-233.

Dines, K. A.; Sheets, P. W.; Brink, J. A.; Hanke, C. W.; Condra, K. A.; et al. High frequency ultrasonic imaging of the skin: Experimental results. Ultrason. Imaging 6:408-434; 1984.

Drewniak, J. L.; Carnes, K. I.; Dunn, F. In vitro ultrasonic heating of fetal bone. J. Acoust. Soc. Am. 86:1254-1258; 1989.

Duck, F. A. Physical properties of tissue. London: Academic Press; 1990.

Food and Drug Administration (FDA) 510 (k) guide for measuring and reporting acoustic output of diagnostic ultrasound. Center for Devices and Radiological Health, Rockville, MD; 1985.

National Council on Radiation Protection. Biological effects of ultrasound: Mechanisms and Clinical Implications. NCRP report no. 74. Bethesda, MD: National Council on Radiation Protection and Measurements; 1983.

National Council on Radiation Protection. Exposure criteria for medical diagnostic ultrasound: I. Criteria based on thermal mechanisms. NCRP report no. 113. Bethesda, MD: National Council on Radiation Protection and Measurements; 1992.

Neter, J.; Wasserman, W.; Kutner, M. H. Applied linear statistical models. Regression, analysis of variance, and experimental designs. Homewood, IL: Irwin; 1990.

Pohlhammer, J. D.; O'Brien, W. D. The relationship between ultrasonic attenuation and speed in tissues and the constituents: water, collagen, protein and fat. In: Fullerton, G. D.; Zagzebski, J. A., eds. Tissue imaging and characterization with computerized tomography and ultrasound. AAPM Technical Monograph No. 6 . New York: Amer. Assoc. Physicists in Med.; 1980:409-435.

Siddiqi, T. A.; O'Brien, W. D., Jr.; Meyer, R. A.; Sullivan, J. M.; Miodovnik, M. In situ exposimetry: The ovarian ultrasound examination. Ultrasound Med. Biol. 17:257-263; 1991.

Siddiqi, T. A.; O'Brien, W. D., Jr.; Meyer, R. A.; Sullivan, J. M.; Miodovnik, M. Human in situ dosimetry: Differential insertion loss during passage through abdominal wall and myometrium. Ultrasound Med. Biol. 18:681-689; 1992.

Smith, S. W.; Stewart, H. F.; Jenkins, D. P. A plane layered model to estimate in situ ultrasound exposures. Ultrasonics 23:31-40; 1985.

Stewart, H. F.; Stratmeyer, M. E., eds. An overview of ultrasound: Theory, measurement, medical applications and biological effects. Health and Human Services Publication (FDA) 82-8190. Washington, DC: U.S. Government Printing Office; 1982. 